\title{
Effects of Aggregate Gradation on the Physical Properties of Semiflexible Pavement
}

\author{
Nadiah Md. Husain, ${ }^{1,2,3}$ Mohamed Rehan Karim, ${ }^{2,3}$ \\ Hilmi B. Mahmud, ${ }^{2,3}$ and Suhana Koting ${ }^{2,3}$ \\ ${ }^{1}$ Civil Engineering Department, UCSI University, 56000 Kuala Lumpur, Malaysia \\ ${ }^{2}$ Center for Transportation Research, Faculty of Engineering, University of Malaya, 50603 Kuala Lumpur, Malaysia \\ ${ }^{3}$ Civil Engineering Department, University of Malaya, 50603 Kuala Lumpur, Malaysia
}

Correspondence should be addressed to Nadiah Md. Husain; nadiah.husain09@gmail.com

Received 30 May 2013; Accepted 18 October 2013; Published 9 January 2014

Academic Editor: Aiguo Xu

Copyright (C) 2014 Nadiah Md. Husain et al. This is an open access article distributed under the Creative Commons Attribution License, which permits unrestricted use, distribution, and reproduction in any medium, provided the original work is properly cited.

Semiflexible pavement (SFP), a composite pavement, is formed by filling into a very open porous asphalt skeleton a specifically designed water consistency fluid mortar with a very high early and 28-day strength. The amalgamation of both components will produce a SFP where it will replace the conventional wearing course. The main goal of this investigation is to study the effect of various aggregate gradations towards producing SFP. These include determining the optimum binder, volumetric properties, and durability and strength of each aggregate gradation. The final results were statistically analyzed and two factor variance analyses (ANOVA) were performed to check on the significance at certain confidence limits. The results confirmed that different aggregate gradations significantly affect the properties mentioned.

\section{Introduction}

The most common pavement that is widely used is the flexible bituminous pavement or also known as asphalt pavement. It consists of asphalt as a binder mixed with a certain aggregate gradations to form a durable surface material laid down to sustain traffic loads. Bitumen is well known to be flexible and elastic which is why the total pavement structure deflects under loading Due to that, flexible pavement requires more layers to sustain the amount of load compared to concrete pavement. Concrete pavement on the other hand typically comprises of binder (cement), water, and aggregates. This type of structure deflects very little under loading due to its high modulus of elasticity of its surface course. Because of its relative rigidity, the pavement structure distributes loads over a wide area with only one or at most two structural layers compared to flexible pavement.

Common road surfacing problems include surface cracks, rutting, and raveling which caused potholes and particle losses. Surface deterioration significantly affects the ease of travel and caused major rehabilitation for both flexible and rigid pavement. Rigid pavement on the other hand can be susceptible to relatively slow setting times during the construction phase and poor riding quality (and noise) caused by the joints required to accommodate differential expansion/contraction during service [1]. Road surfacing or the surface course demands an adequate quality and durability to ensure satisfactory riding quality. Studies have been done to increase the quality and durability of both mentioned pavements. These include cooperating crumb rubber modified binder, polymer modified binder, plastic modified binder, and so forth, and the usage of different type of aggregate gradations [2-5].

An alternative pavement that is currently new in Malaysia is the jointless semirigid pavement surfacing or also known as the semi-flexible pavement (SFP). The new surface course has been introduced to cater for major pavement deterioration problems in Malaysia such as raveling and rutting. SFP is a combination of both flexible and rigid pavements. It basically focuses on the production of surface course or the wearing course where the combination consists of both the flexibility 
from the bituminous component and the rigidity from the cement constituent.

SFP has also been known as semirigid pavement, Grouted Macadam, or cement concrete composite by other agencies and regions. Most importantly, all mentioned names do carry the same meaning, with just differences in its terminology. SFP has been firstly attempted in France and extensively being used in Europe since the past 50 years. According to Ahlrich and Anderton [2], SFP usage has been spread throughout Europe into several countries, that is Africa, the South Pacific, the Far East, and North America, in the 1970s and 1980s. According to Nunez [6], countries, such as UK and Spain, have used semi flexible pavement systems in their main road networks, have reported positive experiences in terms of functional and structural performance. SFP is suggested to be used at locations where require particularly heavy or concentrated loading, at areas where likely to have spillage of aggressive materials or at areas that require high surface rigidity [7-9].

\section{Background}

SFP is manufactured by producing a very high workability fluid grout whilst maintaining its relatively high early and 28day strength, impregnated into a very open porous asphalt skeleton. Porous asphalt skeleton is manufactured by using bitumen as binder coating the course and fine aggregates. A very high porosity of the porous asphalt skeleton is required in order to allow the fluid grout to impregnate into the porous mix under the influence of gravitational force without the aid of compaction or vibration. According to Road Engineering Association of Malaysia (REAM) [5], it is essential that the porous asphalt skeleton achieved a certain percentage of air voids content (25-30\%) in order to allow the ease of fluid grout penetration. Compaction or vibration towards the porous asphalt skeleton may result in its disintegration due to the high air voids content. SFP is believed to have high capacity and great potential to reduce permanent deformation under high temperature and heavy traffic loads.

The desired voids in mix (VIM) are essential for producing SRP as it will enhance the ease of filling the voids by fluid grout via gravitational force without the aid of vibration as it may damage the porous asphalt due to high percentage of air voids. Referring to Figure 1, 3 different aggregate gradations (G1, G2, and G3) were chosen for the purpose of producing porous asphalt mixture in order to determine the significant differences towards the properties of SFP. G1, G2, and G3 are the aggregate gradations ranging from the most porous to the least porous, respectively. Properties of SFP include its volumetric properties, quality, and durability. The best composition of fluid grout will be selected to fill the porous asphalt skeleton porosity and the significant effects towards the production of SFP will be discussed.

Studies done by Hassan et al. [8] showed that the combination between these two crucial elements gives a conspicuously higher strength at 28 days compared to the conventional pavement. One of the important criteria that needed to be fulfilled in producing porous asphalt is the amount of binder

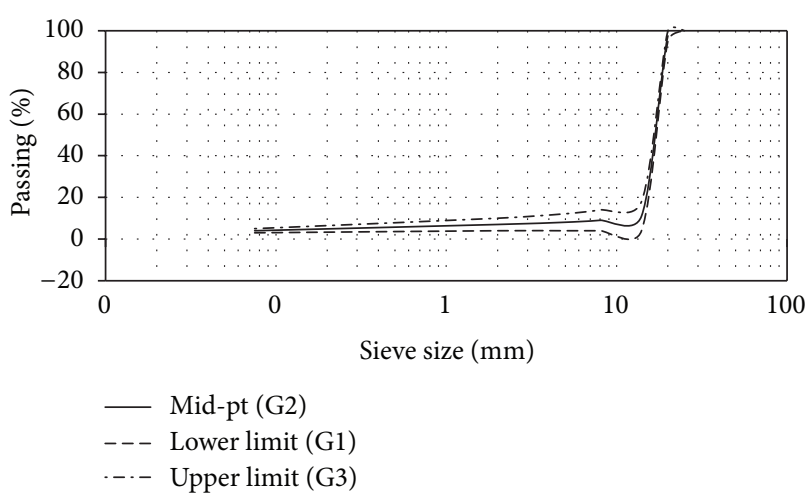

FIgURE 1: Aggregate gradations for porous mix.

usage to coat the aggregate. It is crucial to have the optimum binder coating the aggregates as to prevent rapid oxidation of binder which eventually weakens the bond between the binder and aggregates. Thus, an optimum binder test has to be carried out in order to accomplish the right amount of binder that is required for a certain type of aggregate gradation. According to Ali et al. [10], many factors might contribute to this hardening of the bitumen which include oxidation, volatilisation, polymerization, and thixotropy. This is obviously caused by the exposure of bitumen towards possible distress especially weathering. Thus, with the implementation of SFP; where aggregate and bitumen are fully coated with the fluid grout, will definitely help to overcome the hardening of bitumen.

Optimum binder is also required to maintain the aggregates to be intact in its original position without having neither thin coats nor excessive coating. Thin coats binder film thickness will not give enough stiffness to maintain the aggregate from friction and durability. Bitumen will get aged and oxidation may easily take place. Studies [5, $8,11,12$ ] shows that the inadequate binder film thickness will eventually cause ravelling and cracks. Thicker binder film thickness will risk of excessive binder run-off during mixing, transportation, and also laying. Henceforth this will eventually cause clogging of voids after the laying process and reduce the important properties of porous mix.

In Malaysia, however, the first trial application of SFP took place in 2001 on a short stretch in Kuala Lumpur to overcome some of the deficiencies of conventional flexible pavement using the materials supplied by a well-known international company. Therefore, in the year 2007, REAM [5] introduced a standard specification for semirigid wearing course aiming to achieve the quality and consistency in road and highway design and construction.

\section{Objectives}

To distinguish the pavement made by the combination of both flexible and rigid pavements for 3 different aggregate gradations (G1, G2, and G3) and its significance towards producing SFP. 
TABLE 1: Chemical composition of OPC and SF (\% of mass).

\begin{tabular}{lccccccc}
\hline $\begin{array}{l}\text { Chemical } \\
\text { composition/ } \\
\text { materials }\end{array}$ & $\mathrm{SiO}_{2}$ & $\mathrm{Al}_{2} \mathrm{O}_{3}$ & $\mathrm{Fe}_{2} \mathrm{O}_{3}$ & $\mathrm{CaO}$ & $\mathrm{MgO}$ & $\mathrm{SO}_{3}$ & $\mathrm{MnO}$ \\
\hline OPC (\%) & 16.50 & 3.65 & 3.63 & $\mathbf{6 9 . 4 3}$ & 1.29 & 4.23 & 0.04 \\
$\mathrm{SF}(\%)$ & $\mathbf{9 2 . 5 4}$ & 0.31 & 0.13 & 2.33 & 0.41 & 0.60 & 0.09 \\
\hline
\end{tabular}

\section{Experimental Details}

\subsection{Materials}

4.1.1. Fluid Grout. A wide range of fluid grout composition was prepared by trial and error in order to achieve the requirement of workability. Binder is defined as a combined mass of dry cementitious and pozzolanic materials. Two types of cementitious materials were used in this investigation. These include ordinary Portland cement (OPC) and silica fume (SF) which was supplied in a powder formed, from a local manufacturer, and comply with the requirements specified in the BS EN 197-1:2000. The chemical and physical properties of OPC and SF are given in Table 1. The bold values for both OPC and SF are the constituent that contributes to the first stage of cement hydration and pozzolanic activities respectively which eventually will furnish the strength increment of fluid grout. According to Kadri et al. [13], the use of silica fume in combination with a superplasticizer is now a usual way to obtain high-strength concretes. The improvement of mechanical properties of concretes with silica fume accounts for the increasing consumption of this admixture in concrete. Materials like polymers may also be introduced into the composition. According to Hong and Park [14], incorporation of polymers does not only help in the increment of strength and reduction of bleeding and shrinkage, it also gave a drawback to the composition where it contributes to the cohesiveness of the fresh grout composition.

A superplasticizer was used to help with the production of high workability of cementitious grout. This chemical admixture is also known as a high range water reducer (HRWR) and supplied by a local manufacturer which is the polycarboxylic ether (PCE) based. According to ASTM C 494-92, PCE-based HRWR is classified under Type F. It emphasizes the acceleration of the cement hydration process which helps in early stripping of forms/early strength.

In the matter of producing a flowable fluid grout for the purpose of SFP wearing course, a highly workable fluid grout is needed. A suggested workability for the purpose of SFP by REAM [5] is between $11 \mathrm{~s}$ and $16 \mathrm{~s}$, in order to ensure a full penetration through the voids from the porous asphalt skeleton without the aid of vibration. According to Hassan et al. [8], the main requirements of the grout mixtures are to rapidly penetrate the porous asphalt skeleton and when cured improve the strength and deformation properties of the resultant composite. The produced fluid grout should have a very high workability fluid grout and at the same time attain a significantly high compressive strength in the early and later days.
4.1.2. Porous Asphalt Skeleton. Materials used for the production of porous asphalt skeleton in this investigation are the bitumen $80 / 100$, crushed aggregates with a specially designed porous mix gradation, and also Portland cement which acts as a filler. All materials were supplied by a local supplier. The aggregate gradation is specifically selected so that the resulting compacted composite will give a very high porosity or the voids in the mix (VIM) ranging between $25 \%$ and $32 \%$ of the total structure. G1, G2, and G3 are the aggregate gradations ranging from the most porous to the least porous, respectively and Figure 1 shows clearly the difference in the 3 mentioned aggregate gradations.

The ambient (with the country's high in humidity), existing pavement layers and the hot mix asphalt temperatures are very critical to obtaining compaction and longevity of the newly paved surfaces and patches. The mixing and compacting temperature and sufficient number of blows (compaction) are also among the crucial elements in producing porous asphalt skeleton. The mixing temperature has to be controlled in order to make sure that the bitumen binder does not volatilize or evaporate due to high temperature. This will eventually affect the bitumen properties and furthermore affect the whole pavement structure. Note that if the ambient and the existing pavement structures are colder than the required or specified temperature, it will cause the newly paved asphalt pavement to cool in abrupt and causing it to set up and making it very difficult to obtain the required or specified compacted density. Compaction temperature also plays an important role. If the hot mix asphalt cools quicker (due to ambient or the existing pavement layer temperature), density will not be achieved, and patch will ravel and fall apart. Thus, the suggested mixing temperature by the author is $160^{\circ} \mathrm{C}$ and compaction temperature is not less than $140^{\circ} \mathrm{C}$. The suggested number of blows during compaction for producing a high porosity porous asphalt skeleton is not less than 50 blows upper and lower surface of the sample [5].

\subsection{Procedure}

4.2.1. Fluid Grout. All dry materials were mixed using a mechanical mixer for 2 minutes with slow mixing rate (94 RPM) in order to produce a homogeneous composite. $2 / 3$ of the mixing water was added into the dry mix followed by another $2 / 3$ of the superplasticizer and let it be homogeneously mixed for 3 minutes. This mixing procedure was found to minimize the absorption of chemical admixture by binders thus improving the fluid grout workability [8]. The remaining water and superplasticizer were then added (with higher mixing rate $386 \mathrm{RPM}$ ) for another 5-10 minutes for a better workability result and it can then proceed with the flow cone test.

The flow cone test is carried out by measuring the time of a known quantity of grout to empty a standard flow cone through a funnel. This test is used to determine the workability or viscosity of the grout. The workability is an indication of how well the mix will flow when it is pumped into a duct or when it penetrates into a porous asphalt skeleton. A funnel that meets the requirement of REAM [5] is required to perform this test. According to REAM [5], the efflux time 
for a $1 \mathrm{~L}$ fresh fluid grout to discharge from the funnel shall be between $11 \mathrm{~s}$ and $16 \mathrm{~s}$.

Immediately after the flow cone test had been completed, the fresh fluid grout was then cast into cubes of $50 \times 50 \times$ $50 \mathrm{~mm}$ for compressive strength testing. These cubes were then tested at the age of 1, 3, 7, and 28 days in accordance with BS 1881: Part 116:1983 [15].

4.2.2. Porous Asphalt Skeleton. Optimum binder is achieved by a test developed by REAM [5] called the binder drainage test (BDT), similar to the Transport Research Laboratory, UK. Each of the aggregate gradations will undergo a 3 times repetition test for a series of binder contents and the amount of material drained measured each time. The retained binder $(R \%)$ is calculated from the retained binder equation from (1). According to Hardiman and Mohamed [12], the term "target binder content" or the "optimum binder" refers to the maximum binder content that can be safely accommodated without the risk of excessive binder run-off during mixing, transport, and laying. The drain down percentage is then calculated from (2) to determine whether the mixture has adequate stiffness to prevent drain down:

$$
R=\frac{100 \times B[1-D /(B+F)]}{(1100+B)},
$$

where $D$ : mass of binder $n$ filler drained (g), $B$ : initial mass of binder and filler drained (g), and $F$ : initial mass of filler in the $\operatorname{mix}(\mathrm{g})$

$$
\text { Drain down }(\%)=\frac{\left(M_{\text {final }}-M_{\text {initial }}\right)}{1100} \text {. }
$$

Porous asphalt skeleton was produced by using the Marshall method (ASTM D 1559) with 50 numbers of compaction blows on upper and lower face of the sample. The 50 number of compaction blows is an acceptable compaction value for medium traffic flow [8] and an acceptable value to produce a desired voids in the mix (VIM). The specimens were left for 24 hours after compaction in a room temperature before following testing to be done.

4.2.3. Semiflexible Pavement. The compressive strength test method was done in accordance with BS 1881-Part 116 (1983) [15] on both 1st and 28th days similar to the hardened cubes of fluid grout.

The L.A. abrasion test method was used to ensure the adequate durability of the SFP and it was carried out in accordance with ASTM C 131-06 [16] standard using the L.A. Machine. It is a common test used to indicate aggregate toughness and abrasion characteristics. This test is crucial to substantiate the production of a good quality of wearing course by resisting crushing, degradation, and disintegration.

\section{Requirements}

The main requirement for fresh fluid grout was to have a pourable consistency that allows rapid penetration into the porous asphalt skeleton. REAM [5] suggested a workability
TABLE 2: Optimum binders (OB) for 3 different aggregate gradations and its drain down.

\begin{tabular}{ccccccc}
\hline & OB1 & OB2 & OB3 & Average OB & $r^{2}$ & Drain down (\%) \\
\hline G1 & 2.75 & 2.75 & 2.50 & 2.67 & 0.9036 & 0.15 \\
G2 & 3.30 & 3.40 & 3.20 & 3.30 & 0.8910 & 0.05 \\
G3 & 3.80 & 3.85 & 3.85 & 3.83 & 0.9065 & 0.01 \\
\hline
\end{tabular}

TABLE 3: Mean properties of porous asphalt skeleton.

\begin{tabular}{lcccc}
\hline $\begin{array}{l}\text { Asphalt mix } \\
\text { characteristic }\end{array}$ & G1 & G2 & G3 & $\begin{array}{c}\text { Aussan et al. (2002) } \\
{[8]}\end{array}$ \\
\hline Porosity (VIM) $(\%)$ & 33.4 & 32.5 & 28.8 & 31.7 \\
Bulk density $\left(\mathrm{g} / \mathrm{cm}^{3}\right)$ & 1.63 & 1.72 & 1.79 & 1.73 \\
Specific gravity $(\mathrm{g} / \mathrm{mL})$ & 2.52 & 2.52 & 2.52 & 2.52 \\
\hline
\end{tabular}

of a known fluid grout to empty a flow cone to be between 11 and 16 seconds is the best fluidity filling the voids of porous asphalt. Porosity of the porous asphalt skeleton is suggested to be between $25 \%$ and $30 \%$ of the total sample. The high porosity of air voids will necessitate the fluid grout to fill the voids via gravitational force and when hardened give enough strength to the composite pavement. The final SFP compressive strength for day 1 and day 28 suggested by REAM [5] is $5 \mathrm{MPa}$ and $7 \mathrm{MPa}$, respectively. The high compressive strength of SFP may help in the rehabilitation process of surface pavement compared to the conventional flexible pavement.

\section{Results and Discussions}

6.1. Binder Drainage Test. G1, G2, and G3 are the aggregate gradations ranging from the most porous to the least porous, respectively. Table 2 shows the overall trials done to determine the optimum binder for the 3 different aggregate gradations. It is obvious that the increment of fine aggregates in the aggregate gradations has caused accretion towards the bitumen binder. Fine aggregates contribute to a wider surface area thus preparing a higher amount of bitumen binder to coat all the aggregates in the mix $[17,18]$. This eventually will necessitate a higher usage of binder from G1 up to G3.

The drain down percentage suggested by REAM [5] is anything less than $0.3 \%$. Table 2 also shows that the drain down percentage decreased from G1 to G3. Higher drain down percentage explained that the gradation mix is higher in porosity and a lower amount of binder is being used for the purpose of coating the aggregates. Lower percentage drain down on the other hand concluded that the gradation mix is lower in porosity and the amount of binder is otherwise.

6.2. Properties of Porous Asphalt. Porous asphalt skeleton is produced in compliance with that ASTM D 1559-89 [19]. The compacted specimen of unfilled porous asphalt skeleton needs to undergo a series of tests in order to validate its properties. Table 3 shows the properties of the porous asphalt skeleton done on the compacted samples before undergoing the process of filling the voids with the selected fluid grout. 
Porosity of aggregate gradations increases from G1 to G3. Properties of porous asphalt are listed in Table 3.

VIM was achieved in accordance with ASTM D-3203-94 [20] standard. The targeted values of VIM for porous asphalt are between $25 \%$ and $30 \%$ [21] which is much higher than the conventional porous asphalt skeleton where it only requires VIM between $18 \%$ and $25 \%$ [22]. The high percentage of VIM is required for the purpose of allowing a full penetration of fluid grout by gravitational force without the aid of vibration. Porosity achieved in Table 3 has shown a descending pattern from G1 to G3 that varies from $28.8 \%$ to $33.4 \%$. The bulk density $\left(G_{\mathrm{mb}}\right)$ test was done in accordance with ASTM D 118807 [23] standard. $G_{\mathrm{mb}}$ has shown a close relationship with the changes of air voids. It was found that $G_{\mathrm{mb}}$ is inversely related to the changes of porosity.

The porosity of G3 confirmed that it represents the finest aggregate gradation while the G1 represents the coarsest aggregate gradation. This is proven by the porosity value of each aggregate gradation represented in Table 3 . These results demonstrate that, as the aggregate gradation gets coarser, so does the increment in porosity or voids in the total mix. Higher value of porosity suggested the ease of fluid grout penetration compared to the lower air voids value of the porous mixes. The preparation of the high porosity mix via an interlocking system of aggregates will help in filling the air voids with fluid grout mixtures via gravitational force.

Bulk density or bulk specific gravity of the unfilled compacted porous asphalt is defined as the ratio of the mass of air of a unit volume of a permeable material (including both permeable and impermeable) at a stated temperature of the mass in air (of equal density) of an equal volume of gas-free distilled water at a stated temperature. Referring to Table 3, bulk density has shown a close relationship with the porosity of unfilled compacted porous asphalt skeleton. Bulk densities of the 3 different aggregate gradations were found to be inversely proportional to the changes in porosity. It is obviously due to densification of the mix resulted in a reduction of porosity and vice versa [23-25]. The 3 asphalt mix characteristics that is, porosity, bulk density, and specific gravity results were then compared to those achieved by Hassan et al. [8] as shown in Table 3.

Studies done by Hassan et al. [8] showed similar values compared to the values achieved by the author's selected aggregate gradations. This has proven that the chosen porous mix gradations by the author are suitable and acceptable for the current investigation that requires high porosity of asphalt skeleton. The specific gravity on the other hand was similar among the 3 aggregate gradations and with the values obtained by them [8].

6.3. Semiflexible Pavement (SFP). The best selection of fluid grout composition (Flow $=16.5 \mathrm{~s}$, compressive strength of day $1=57 \mathrm{MPa}$, day $28=117 \mathrm{MPa}$ ) that complies with the requirements will be selected in order to understand the significant difference towards the aggregate gradations. SFP will undergo several tests in order to validate its properties such as volumetric properties, strength, and its abrasion resistance. These properties indicate the quality and durability of the resulting composite. It is noted that the flow and

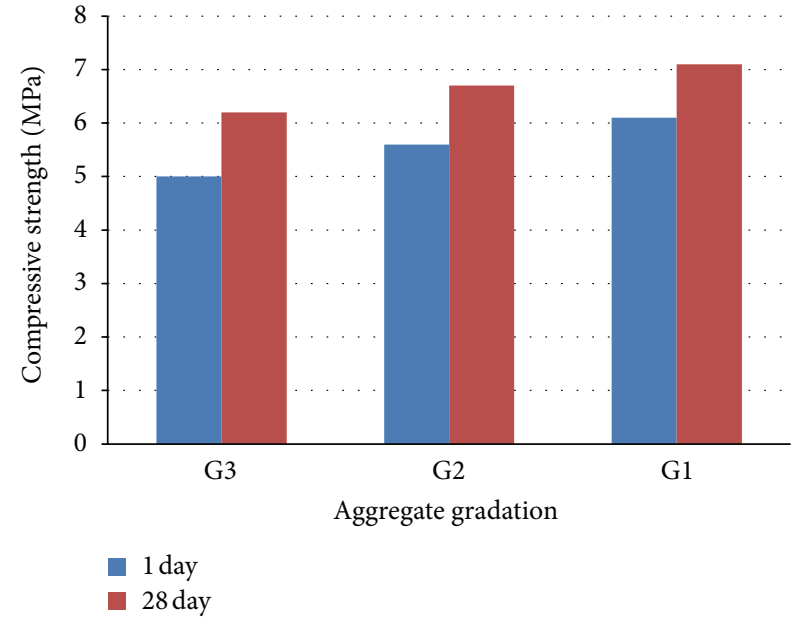

FIgURE 2: SFP strength developments at day 1 and day 28.

compressive strength of the chosen fluid grout comply with the standard guideline by REAM [5]. The compacted porous asphalt skeleton will be filled with fluid grout via gravitational force without the aid of vibration but spreading it all over the surface with the help of metal scrapper.

Figure 2 elucidates the SFP strength developments with the selected fluid grout. Aggregate gradations have shown a significant increment in production of SFP from day 1 to day 28. The decrement in porosity from G1 to G3 has resulted in a reduction of the measured compressive strength. This is due to the fact that decrement of air voids from G1 to G3 has caused a reduction in the amount of area that is prepared for the fluid grout in filling the voids.

The targeted requirement of compressive strength for SFP suggested by REAM [5] for day 1 and day 28 is $5 \mathrm{MPa}$ and $7 \mathrm{MPA}$, respectively. G1 indicated the highest strength of $6.1 \mathrm{MPa}$ on day 1 compared to the other two aggregate gradations which achieved $5.6 \mathrm{MPa}$ and $5 \mathrm{Mpa}$, respectively. As explained earlier, the higher air voids from the porous asphalt skeleton achieved has helped the final composite to be able to attain a better and justified strength. Above all, the 3 aggregate gradations gave a reasonable remark of strength and most importantly achieved the targeted value of day 1 strength.

Figure 2 shows a descending regular pattern of compressive strength on the 28th day strength of SFP from G1 to G3. It can be seen that G1 gave the highest value and this is obviously due to the fact that higher amount of hardened grout has helped with the increment of strength to the final composite pavement. G1 has achieved the targeted requirement suggested by REAM [5]. G2 and G3 have also achieved the targeted value and at the same time have given a better strength compared to the conventional flexible pavement strength, that is, $3 \mathrm{MPa}$. The final results of the SFP will obviously help in producing and improving the quality of pavement currently being used in Malaysia [17].

Tables 4 and 5 summarize the properties of SFP at day 1 and day 28 for the 3 different aggregate gradations. Porosity for SFP at both day 1 and 28 varies from $3 \%$ to $3.5 \%$. The 
TABLE 4: SFP mean properties at 1 day.

\begin{tabular}{ccccc}
\hline & Strength (MPa) & Abrasion (\%) & VIM (\%) & $\begin{array}{c}\text { Bulk density } \\
(\mathrm{g} / \mathrm{mL})\end{array}$ \\
\hline G1 & 6.1 & 20.33 & 3.0 & 1.66 \\
G2 & 5.6 & 21.85 & 3.1 & 1.75 \\
G3 & 5.0 & 24.18 & 3.3 & 1.81 \\
\hline
\end{tabular}

TABLE 5: SFP mean properties at 28 days.

\begin{tabular}{ccccc}
\hline & Strength (MPa) & Abrasion (\%) & VIM (\%) & $\begin{array}{c}\text { Bulk density } \\
(\mathrm{g} / \mathrm{mL})\end{array}$ \\
\hline G1 & 7.1 & 19.27 & 3.1 & 2.21 \\
G2 & 6.7 & 20.43 & 3.3 & 2.22 \\
G3 & 6.2 & 21.36 & 3.5 & 2.21 \\
\hline
\end{tabular}

reduction in porous asphalt porosity is basically due to the process of impregnation of fluid grout. The porosity of SFP is controlled to be less than $8 \%$ in order to achieve incomparable to that of high performance concrete [8]. Thus, it can be concluded that, as the aggregate gradation gets coarser, so does the increment in VIM and eased the filling process of fluid grout.

$G_{\mathrm{mb}}$ of SFP on day 28 is higher by $26 \%$ compared to SFP on day $1 . G_{\mathrm{mb}}$ has shown a close relationship with the VIM. $G_{\mathrm{mb}}$ of the 3 different aggregate gradations was found to be inversely related to the changes of VIM. This is obviously caused by the densification of the fluid grout $[26,27]$. By the 28 th day, cement hydration took place and has given extra weight to the matrices of fluid materials.

The abrasion percentage varied within a small range but has decreased from day 1 to day 28. The targeted requirement is to achieve an abrasion percentage of not more than $30 \%$ of the total mix. Figure 3 gave a better understanding of the abrasion percentage pattern for the 3 different aggregate gradations at both day 1 and day 28. Abrasion percentage has shown a close relationship with the compressive strength whereby it is inversely related to the increment of it. According to Ahmet and Sukru [28], the abrasion resistance is influenced by a number of factors, which includes compressive strength, surface finish, aggregate properties, types of hardeners, and curing method. A number of previous studies [29-32] have indicated that the abrasion resistance of concrete/composite pavement is primarily dependent on the compressive strength of the concrete/composite pavement.

The aggregates from semirigid wearing course prototype that was initially coated with bitumen (porous asphalt skeleton) was then covered fully by the existing fluid grout that fills the voids. The double layering towards the aggregates may be one of the reasons that have initiated the high abrasion resistance of the prototype samples. According to the Australian Concrete Masonry Associates Specification for Concrete Segmental Paving Units (MA20) [33], there is no strong correlation found between compressive strength and abrasion resistance, although there appeared to be some relationship between abrasion resistance and road pavement. From the author's laboratory experiment and

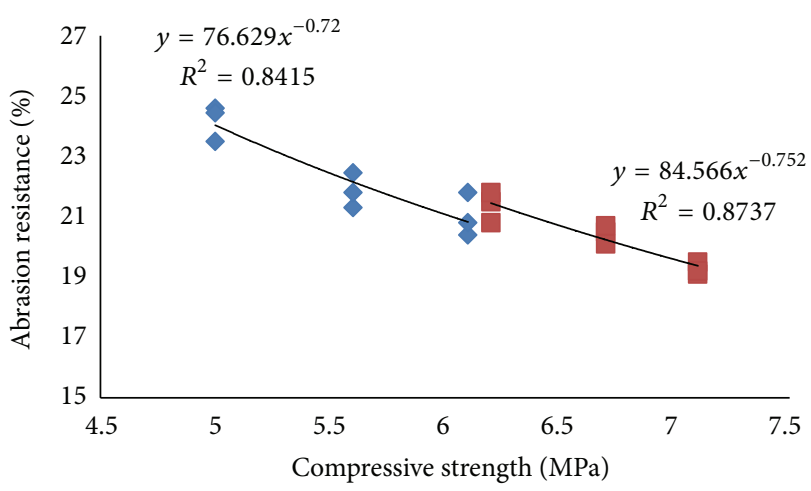

Abrasion \% at 28 day

Abrasion \% at 1 day

FIGURE 3: Abrasion of SFP at day 1 and day 28.

TABLE 6: ANOVA analysis results.

\begin{tabular}{lcccc}
\hline Source of variation & $F$ value & $F$ critical & $P$ value & $P$ max \\
\hline $\begin{array}{l}\text { Binder drainage test } \\
\text { (optimum binder) }\end{array}$ & 78.76 & 18.51 & 0.012 & 0.05 \\
$\begin{array}{l}\text { Porous asphalt } \\
\text { skelton (porosity) }\end{array}$ & 129.13 & 18.51 & 0.0076 & 0.05 \\
\begin{tabular}{l} 
L.A. abrasion test \\
\hline
\end{tabular} & 36.7 & 3.32 & $4.06 E-06$ & 0.05 \\
\hline
\end{tabular}

findings (Figure 3), the abrasion resistance obtained shows a relatively good result, based on the regression analysis $\left(R^{2}\right)$ or the coefficient determination which suggest that there is a high polynomial relationship between the dependent and independent variables.

\section{Analysis of Variance (ANOVA)}

Previously discussed results have been analyzed using ANOVA or also known as the analysis of variance, a model which was widely used in analyzing data. The ANOVA test that was carried out on the binder drainage test, porous asphalt skeleton, and the results of the L.A. abrasion was using the two-factor ANOVA analysis without replication. The hypotheses for the mentioned test were as follows.

Hypothesis 1. We have the following.

$H_{1}$ (Null hypothesis): the optimum binder is significant with the changes of aggregate gradation.

$H_{o}$ (Proposed Hypothesis): the optimum binder is not significant with the changes of aggregate gradation.

Referring to Table 6, under the optimum binder, since $F_{\text {value }}>F_{\text {crit }}$, thus we accept $H_{1}$, that the overall variance in the results is greater than the experimental variance alone. We can also come to the same conclusion and accept $H_{1}$, by noting that the $P$ value, 0.012 , is less than the significance level, $\alpha=0.05$. Having accepted that, the further conclusion is that there is a significant difference between the sample mean values of optimum binders with the changes in aggregate gradation. 
Hypothesis 2. We have the following.

$H_{1}$ (Null hypothesis): the porosity is significant with the changes of aggregate gradation;

$H_{o}$ (Proposed Hypothesis): the insignificance of porosity towards the changes of aggregate gradation.

Referring to Table 6, under the porosity, since $F_{\text {value }}>$ $F_{\text {crit }}$, thus we accept $H_{1}$, that the overall variance in the results is greater than the experimental variance alone. The acceptance of $H_{1}$ is also proven by noting the $P$ value, 0.0076 , is less than the significance level, $\alpha=0.05$. Having said that, it can be concluded that there is a significant difference between the sample mean values of porous asphalt skeleton with the changes in aggregate gradation.

Hypothesis 3. We have the following.

$H_{1}$ (Null hypothesis): SFP abrasion is significant with the changes of aggregate gradation;

$H_{o}$ (Proposed Hypothesis): the insignificance of SFP abrasion towards the changes of aggregate gradation.

Referring to Table 6, under the L.A. abrasion test, $F_{\text {value }}>$ $F_{\text {crit }}$, thus $H_{o}$ is rejected. The acceptance of $H_{1}$ is also proven by noting the $P$ value, $4.06 E-06$, is less than the significance level, $\alpha=0.05$. Finally, it can be concluded that there is a significant difference between the sample mean values of SFP abrasion with the changes in aggregate gradation.

\section{Conclusion}

SFP has been manufactured and has attained a certain standard required by the authors and a certain guideline by the government. The 3 different aggregate gradations do give a significant effect towards the volumetric properties, durability, and strength towards SFP.

8.1. Volumetric Properties. VIM values for SFP increase from G1 to G3 for both day 1 and day 28. Less porous aggregate gradation has delayed the fluid grout movement via filling the air voids of the porous asphalt skeleton. It can be concluded that, as the aggregate gets coarser, the increment in VIM is higher and the filling process of fluid grout becomes easier.

Bulk density $\left(G_{\mathrm{mb}}\right)$ has shown a close relationship with the VIM. $G_{\mathrm{mb}}$ of the 3 different aggregate gradations was found to be inversely related to the changes of VIM. This is obviously caused by the densification of the fluid grout.

8.2. Durability. The percentage of abrasion resistance was inversely related to the changes in the aggregate gradation from G1 to G3. The abrasion resistance was found to be inversely proportional to the changes in compressive strength of SFP at both early and later ages. It was observed that samples having higher compressive strength presented with much lower value of abrasion resistance.

Hence, it is established that the abrasion resistance is dependent on the amount or the value of compressive strength. The abrasion resistance obtained shows a relatively good result, based on the regression analysis $\left(R^{2}\right)$ which suggest that there is a high polynomial relationship between the dependent and independent variables.

Aggregate gradation type G3 (MAX) was observed to have the least abrasion resistance $(21.26 \%)$ compared to aggregate gradation type G2 (MID) and G1 (MIN) which are having $20.43 \%$ and $19.27 \%$, respectively. This is most likely due to its capacity that may not be able to cater high amount of fluid grout during the impregnation process.

8.3. Compressive Strength. G1 indicated the highest strength for both day 1 and day 28 compared to the other two aggregate gradations, G2 and G3, respectively. The higher air voids from the porous asphalt skeleton achieved has helped the final composite to be able to attain a better and justified strength. The compressive strength increased gradually from G3 towards G1. Thus, it is proven that the 3 different aggregate gradations gave a significant effect towards the compressive strength. Finally, SFP from the 3 aggregate gradations gave much higher compressive strength and durability compared to the conventional flexible pavement. The newly manufactured high-quality composite pavement can be an alternative and substitution to the conventional surface course.

\section{Conflict of Interests}

The authors declares that there is no conflict of interests regarding the publication of this paper.

\section{Acknowledgment}

Grateful acknowledgment is made to Institute of Research Management and Consultancy (IPPP) of the University of Malaya for funding this project under Grant no PS117/2008C.

\section{References}

[1] K. E. Hassan, A. Setyawan, and S. E. Zoorob, "Effect of cementitious grout on the properties of semi-flexible bituminous pavement," in Proceedings of the 4th European Symposium on Performance of Bituminous and Hydraulic Materials in Pavement, pp. 113-120, 2002.

[2] R. C. Ahlrich and G. L. Anderton, "Construction and evaluation of resin modified pavement," Final Report GL-91-13, U.S. Army of Engineers, Waterways Experiment Station, Vicksburg, Miss, USA, 1991.

[3] N. W. Lister and R. R. Addis, "Field observation of rutting and their practical implications," Transport Research Board 1997 640.

[4] C. C. Wong and W.-G. Wong, "Effect of crumb rubber modifiers on high temperature susceptibility of wearing course mixtures," Construction and Building Materials, vol. 21, no. 8, pp. 1741-1745, 2007.

[5] Road Engineering Association of Malaysia (REAM), "Specification of Semi-Rigid Wearing Course," REAM-SP, 2007.

[6] O. Nunez, "Composite pavement systems: synthesis of design and construction practices," Virginia Technology Transportation Institute Research Council, 2009, http://www.virginiadot .org/vtrc/main/online_reports/pdf/09-cr2.pdf. 
[7] K. E. Hassan, J. G. Cabrera, and R. S. Maliehe, "Effect of mineral admixtures on the properties of high-performance concrete," Cement and Concrete Composites, vol. 22, no. 4, pp. 267-271, 2000.

[8] K. E. Hassan, A. Setyawan, and S. E. Zoorob, "Effect of cementitious grout on the properties of semi-flexible bituminous pavement," in Proceedings of the 4th European Symposium on Performance of Bituminous and Hydraulic Materials in Pavement, pp. 113-120, 2002.

[9] P. H. Wright and K. K. Dixon, Highway Engineering, John Wiley and Son, New York, NY, USA, 7th edition, 2004.

[10] A. H. Ali, N. S. Mashaan, and M. R. Karim, "Investigations of physical and rheological properties of aged rubberised bitumen," Advances in Materials Science and Engineering, vol. 2013, Article ID 239036, 7 pages, 2013.

[11] N. W. Lister and R. R. Addis, "Field observation of rutting and their practical implications," Transportation Research Board 640, 1997.

[12] H. M. O. Hardiman and A. A. Mohamad, "Binder drainage test for porous mixtures made by varying the maximum aggregate sizes," Civil Engineering Dimensions, vol. 6, no. 1, pp. 26-31, 2004.

[13] E. H. Kadri, S. Aggoun, S. Kenai, and A. Kaci, "The compressive strength of high-performance concrete and ultrahighperformance," Advances in Materials Science and Engineering, vol. 2013, Article ID 361857, 7 pages, 2012.

[14] S. Hong and S. K. Park, "Behavior of concrete columns repaired with polymer mortar and epoxy fiber panel," Advances in Materials Science and Engineering, vol. 2013, Article ID 748294, 13 pages, 2013.

[15] British Standard Institution, "Testing Concrete. Method for Determination of Compressive Strength of Concrete Cubes," BS 1881-116, BSI, London, UK, 1983.

[16] American Society for Testing and Materials, "Standard Test Method for Resistance to Degradation of Small Size Coarse Aggregate by Abrasion and Impact in the Los Angeles Machine," ASTM C131, ASTM, Philadelphia, Pa, USA, 2006.

[17] N. M. Husain, H. B. Mahmud, M. R. Karim, and N. B. A. A. Hamid, "Effects of aggregate gradations on properties of grouted Macadam composite pavement," in Proceedings of the 2nd International Conference on Chemical, Biological and Environmental Engineering (ICBEE '10), pp. 128-131, Cairo, Egypt, November 2010.

[18] M. O. Hamzah, M. M. Samat, K. H. Joon, and R. Muniandy, "Modification of aggregate grading for porous asphalt," Proceedings of the 3rd Eurasphaly and Eurobotume Congress, Vienna, Austria, 2004.

[19] American Society for Testing and Materials, "Standard Test Method for Resistance of Plastic Flow of Bituminous Mixtures Using Marshall Apparatus," ASTM D1559-89, Philadelphia, Pa, USA, ASTM, 2012.

[20] American Society for Testing and Materials, "Standard Test Method for Percent Air Voids in Compacted Dense and Open Bituminous Paving Mixtures," ASTM D3203, ASTM, Philadelphia, Pa, USA, 1994.

[21] S. N. Suresha, G. Varghese, and A. U. R. Shankar, "Characterization of porous friction course mixes for different Marshall compaction efforts," Construction and Building Materials, vol. 23, no. 8, pp. 2887-2893, 2009.
[22] A. R. Woodsie, W. D. H. Woodward, and J. K. Baird, A Critical Appraisal on the Performance of Porous Asphalt, Highway Engineering Research Centre for the Built Environment, University of Ulster, 2000.

[23] merican Society for Testing and Materials, "Standard Test Method for Bulk Specific Gravity and Density of Compacted Bituminous Mixtures Using Coated Samples," ASTM D1188, ASTM, Philadelphia, Pa, USA, 2007.

[24] G. Huber, "Performance survey on open-graded friction course mixes," National Cooperative Highway Research Program, Synthesis of highway practice 284, Transportation Research Board, National Research Council, National Academy Press, Washingtion, DC, USA, 2000.

[25] N. M. Husain, H. B. Mahmud, and M. R. Karim, "Optimum binder for porous mixtures made by various aggregate gradations and its properties towards producing grouted macadam composite pavement," in Proceedings of the 8th International Conference on Geotechnical and Transportayion Engineering (GEOTROPIKA '10), p. 154, Sabah, Malaysia, 2010.

[26] T. R. J. Fabb, the Case For the Use Porous Asphalt in the U.K. the Asphalt Year Book 1993, The Institute of Asphalt Technology, Staines, UK, 1993.

[27] J. Mills-Beale and Z. You, "The mechanical properties of asphalt mixtures with Recycled Concrete Aggregates," Construction and Building Materials, vol. 24, no. 3, pp. 230-235, 2010.

[28] C. Ahmet and Y. Sukru, "Investigation of abrasion resistance of cement mortar with different pozzolanic compositions and subjected to sulfated medium," Construction and Building Materials, vol. 24, no. 4, pp. 461-470, 2010.

[29] American Society for Testing and Materials, "Standard Test Method for Resistance to Degradation of Small Size Coarse Aggregate by Abrasion and Impact in the Los Angeles Machine," ASTM C131, ASTM, Philadelphia, Pa, USA, 2006.

[30] K. M. Hadchti and R. L. Carrasquillo, "Abrasion Resistance and Scaling Resistance of Concrete Containing Fly Ash," Research Report 481-483, Centre for Transportation Research, Bureau of Engineering Research, University of Texas at Austin, 1998.

[31] P. Laplante, P.-C. Aitcin, and D. Vezina, "Abrasion resistance of concrete," Journal of Materials in Civil Engineering, vol. 3, no. 1, pp. 19-28, 1991.

[32] K. Mehta, "High-performance concrete durability affected by many factors," Aberdeen's Concrete Construction, vol. 37, no. 5, pp. 367-370, 1992.

[33] Cement Masonry Association of Australia (CMAA), Specification for Concrete Segmental Paving Units (MA20), Concrete Masonry Association of Australia, Sydney, Australia, 1986. 

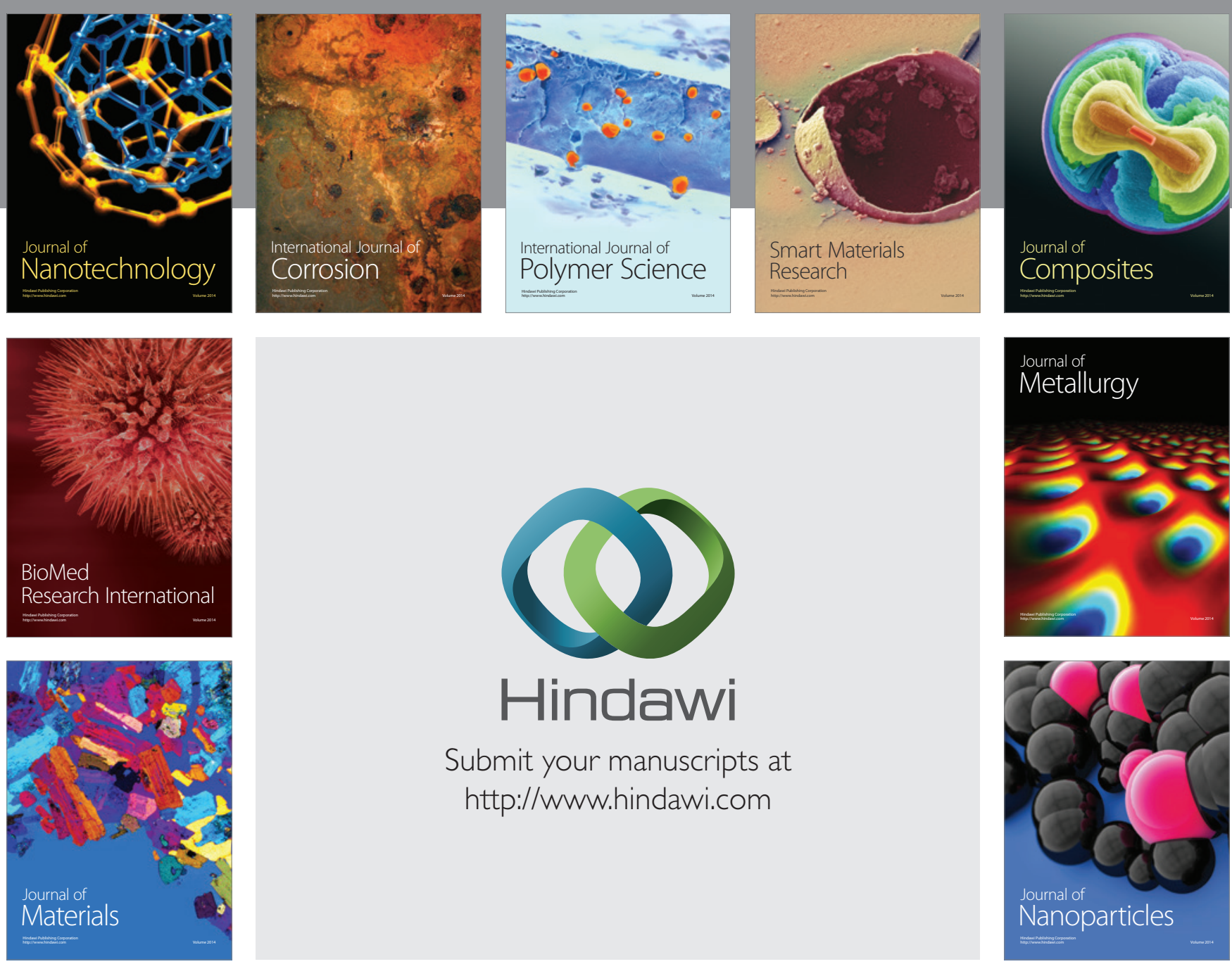

Submit your manuscripts at http://www.hindawi.com
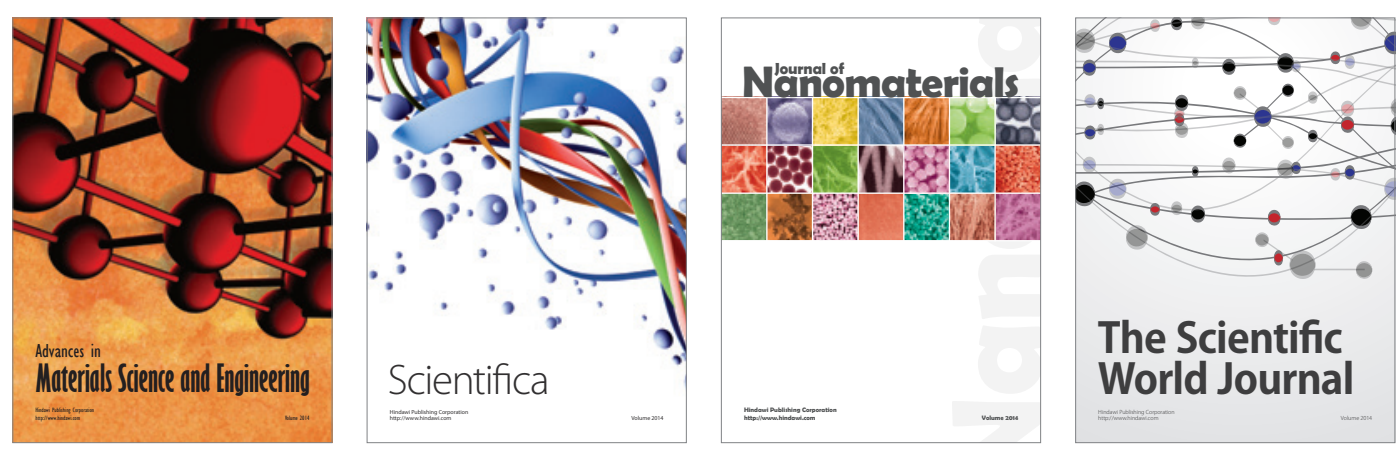

\section{The Scientific World Journal}
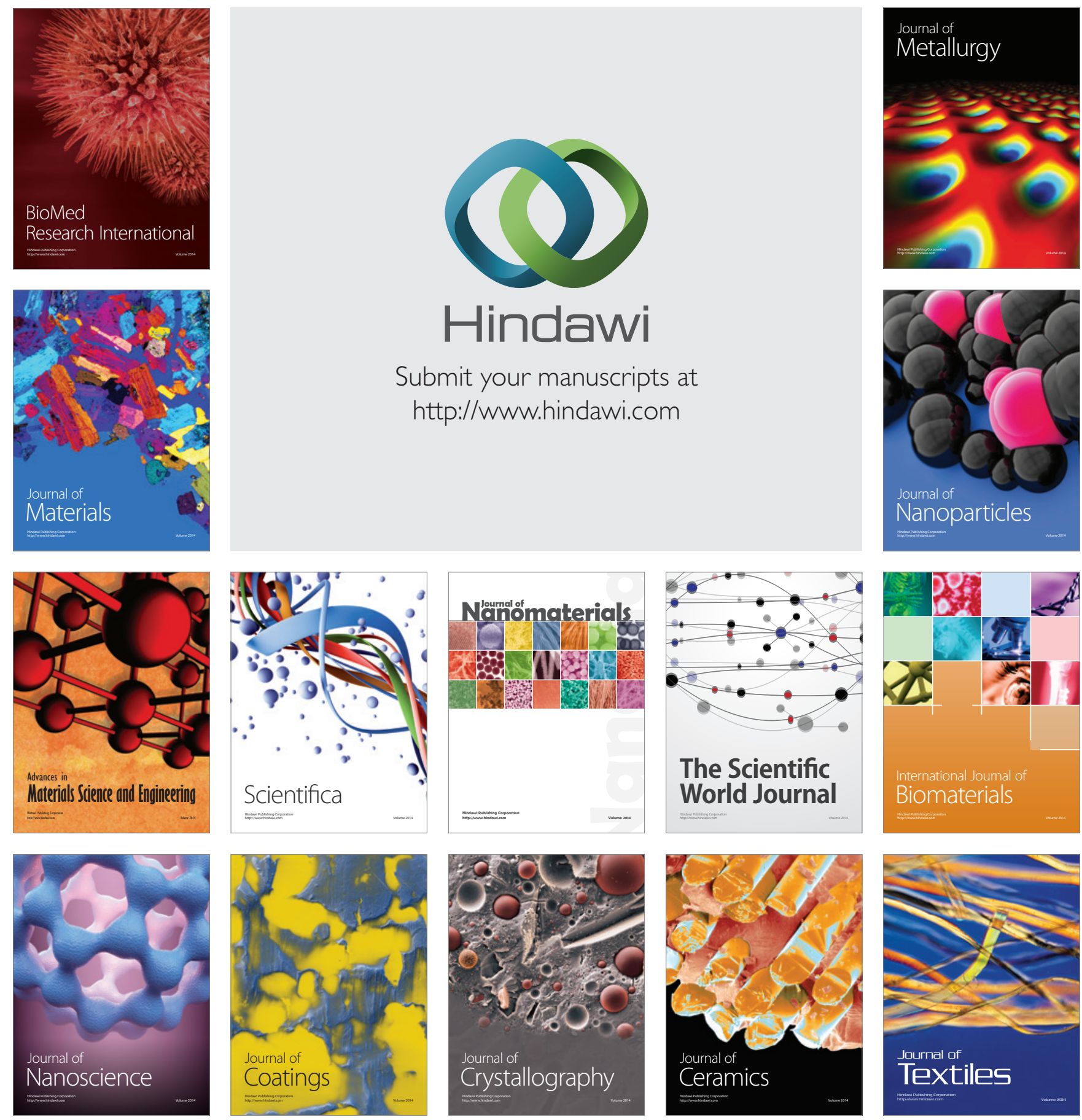